\title{
Desempenho mecânico de misturas asfálticas confeccionadas com agregados sintéticos de argila calcinada
}

\section{(Mechanical performance of asphalt mixtures composed of synthetic calcinated clay aggregates)}

\author{
C. A. Frota, F. R. G. Nunes, C. L. Silva, D. M. Melo, M. G. R. Santos \\ Faculdade de Tecnologia, Universidade Federal do Amazonas - UFAM \\ Av. General Rodrigo Octávio Jordão Ramos, 3000, Manaus, AM 69.077-000 \\ cafrota@ufam.edu.br,fabiorgn@gmail.com,cleudineilopes@gmail.com, \\ diego.meneses@gmail.com,graca_ruffino@yahoo.com.br
}

\begin{abstract}
Resumo
Expressivo número de municípios amazonenses se encontra localizado em áreas carentes em agregados pétreos, o que leva os construtores de pavimentos a adotarem alternativas que, em retrospecto histórico, propiciam pavimentos de deficiente resistência mecânica. Conquanto mais eficaz e apropriado do ponto de vista técnico, o concreto betuminoso usinado à quente é normalmente evitado por conta da indicada carência estadual em agregados pétreos. Em face do peculiar contexto amazonense, revela-se recomendável à circunstância em testilha a adoção de agregados sintéticos de argila calcinada (ASAC), com matéria-prima abundante (argila) no Amazonas. Trabalhos anteriores, realizados pelo Grupo de Geotecnia da Universidade Federal do Amazonas, demonstram que solos argilosos, costumeiramente empregados para produção de material cerâmico, podem produzir agregados sintéticos com adequadas propriedades mecânicas. Nesta pesquisa, amostras com características similares às desses solos foram encontradas na rodovia BR-319, que liga Manaus (AM) a Porto Velho (RO). Trata-se de estrutura, em geral, a ostentar péssimas condições de tráfego, incluída, de maneira justificável, como um dos alvos da política pública de recuperação de rodovias, conduzida pelo Ministério dos Transportes. Neste estudo, dosaram-se misturas asfálticas com agregado sintético e com seixo rolado oriundo do leito dos rios amazonenses, a fim de se comparar o desempenho mecânico de tais misturas por meio da determinação do módulo resiliente (MR). Os resultados, em regra, denotam que as misturas asfálticas confeccionadas com agregado sintético de argila calcinada, quando confrontadas com aquelas confeccionadas com o material natural (seixo), apresentaram: (a) maiores resistências à tração e aos módulos resiliente; (b) baixa tendência à deformação, assim como uma recuperação elástica considerável e (c) menor susceptibilidade às deformações permanentes.
\end{abstract}

Palavras-chave: agregados sintéticos, argila calcinada, módulo resiliente.

Abstract

A substantial number of municipal districts in the State of Amazonas are located in areas which are poor in stony materials. And this has led pavement builders into adopting alternatives which have historically produced pavements with low mechanical strength. Whist more effective and appropriate from a technical standpoint, the asphalt concrete has been usually left aside due to the referred lack of stony materials. Because of the specific situation in the State of Amazonas the adoption of synthetic calcinated clay aggregates (SCCA), with an abundant raw material (clay) in the State of Amazonas is recommended in lieu of the traditional practice. Previous works carried out by the Federal University of Amazonas Geotechny Group have demonstrated that the clay soil commonly used in the production of ceramic materials can yield synthetic aggregates with adequate mechanical properties. In this research work, samples featuring similar characteristics as those of the soils in question have been found along the BR-319 highway connecting the Manaus (AM) city to Porto Velho (RO) city. The transportation structure in general is in deplorable conditions. Justifiably so, the recovery of this highway has been earmarked as one of the targets for the Ministry of Transportation. In this study, asphalt mixtures were blended with synthetic aggregates and pebbles taken from the river bed in order to compare the mechanical performance of such mixtures by means of the determination of the resilient modulus (RM). The results, as a rule, have shown that the asphalt mixtures comprising synthetic calcinated clay aggregates when compared with those comprising the naturally-found material (river bed pebbles) have shown: (a) greater tensile and resilient modulus strengths; (b) low deformation tendency, as well as a considerable elastic recovery and (c) less susceptibility to permanent deformation.

Keywords: synthetic aggregates, calcinated clay, resilient modulus.

\section{INTRODUÇÃO}

No Estado do Amazonas mostra-se reduzido o número de rodovias federais, conforme demonstra a Fig. 1, em face de contar com historicamente parcos investimentos do Poder Público, além de suas avantajadas proporções territoriais, extensa malha hidrográfica e significativas zonas com insuficiência de material granular. Segundo informa o 
Departamento Nacional de Infra-Estrutura dos Transportes - DNIT [1], parcela expressiva da malha rodoviária federal no Amazonas possui diversos trechos classificados como de difícil tráfego. Destarte, no Amazonas afiguram-se escassas as opções para o escoamento da sua produção interna, bem assim para o deslocamento e o recebimento de insumos advindos não apenas dos Municípios do indicado Estado, como também de localidades de outras Unidades Federativas do País. A alternativa principal para o transporte de mercadorias repousa no transporte fluvial e, em escala menor, mais restrita e onerosa, no aéreo. O primeiro transparece a desvantagem de ser comprovadamente lento e restrito a algumas calhas de rios do Estado do Amazonas e a vantagem de deslocar imensa quantidade de mercadorias. $\mathrm{O}$ segundo, apesar de ser a mais rápida forma de transporte de médias e longas distâncias, evidencia-se consideravelmente mais oneroso e menos apropriado para o transporte de grandes quantidades de carga, se comparado ao fluvial.

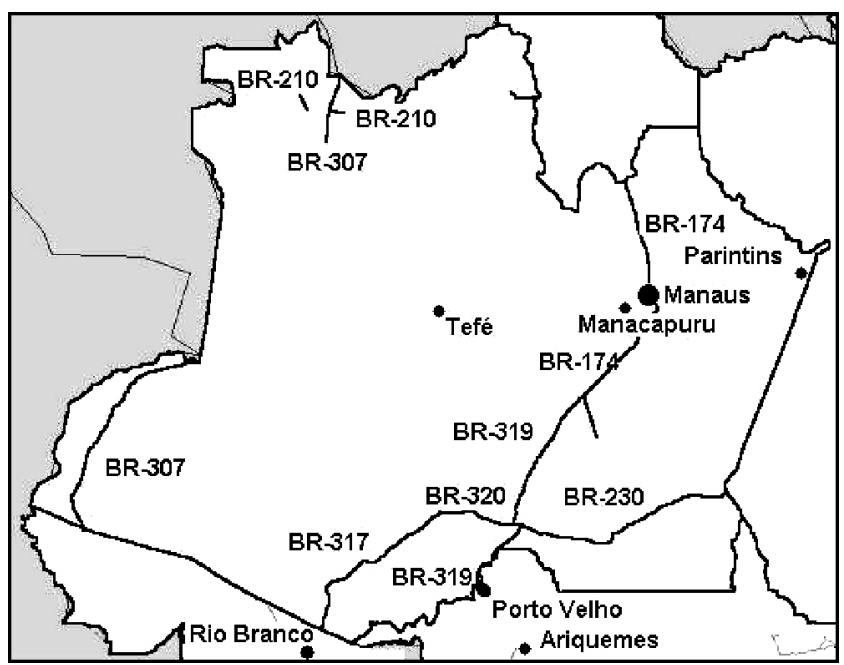

Figura 1: Rodovias federais no Estado do Amazonas. Fonte: Departamento Nacional de Infra-Estrutura dos Transportes (DNIT), 2006. [Figure 1: Federal highways in the State of Amazonas.]

Assim sendo, o transporte rodoviário contempla adequada opção estadual para o translado de cargas e pessoas a tempo mais curto que o hidroviário. Dentre as rodovias do Estado do Amazonas, destaca-se a BR-319, que se encontra presente nos planos de restauração propostos pelo Ministério dos Transportes. Conquanto hoje ostente difíceis condições de tráfego, conecta Manaus (AM) a Porto Velho (RO) - no caso desta, em conjunto com a BR-174 - a Boa Vista (RR) e, em conseqüência, ao restante do País. Quando estiver em pleno funcionamento, o corpo estradal em perspectiva causará economia significativa de tempo e recursos para o transporte de produtos para os Municípios da região CentroOeste, uma vez que é muito lento o transporte fluvial até o Município de Belém (PA) e de lá para outros pontos do País. Contudo, o uso de estradas no Estado do Amazonas esbarra na carência de material pétreo em boa parte dos
Municípios por onde trafegam as rodovias federais. A BR319 , por exemplo, atravessa toda uma faixa do Amazonas onde predominam solos finos e poucas referências rochosas. Portanto, a construção dos pavimentos, relativos a essa via, se depara com o ponderável óbice, atinente à pequena quantidade de agregado graúdo, componente essencial para a resistência estrutural das misturas asfálticas, que cumprem função de camada-revestimento destes pavimentos.

Há ausência de suficiente material granular no Estado do Amazonas, porquanto a maioria de seus Municípios se situa em bacia sedimentar, com rochas datadas especialmente do período do Paleozóico e do Cenozóico [2]. Os horizontes rochosos, de uma maneira geral, possuem baixo grau de consolidação e pouca resistência mecânica. Por conta do processo de intenso intemperismo, tais horizontes são recobertos por camada de espesso solo residual, tornando sua extração inviável sob o prisma econômico.

A comunidade científica, ao longo dos últimos anos, tem vislumbrado nesse material superficial, constituído de solo com matriz argilosa e presente em boa parte da região, provável fonte de matéria-prima para produção de agregados sintéticos de argila. O levantamento bibliográfico deste estudo aponta argilas encontradas em regiões de várzea e margens de rios como sendo materiais potencialmente aptos à produção de bons agregados [3].

Pesquisas recentes também demonstram que parte dos solos amazônicos não possui as características desejadas para produção de agregados expandidos, mas podem ser perfeitamente utilizados para agregados calcinados [4]. Além do que concerne à mineralogia da matéria-prima, diferença essencial entre ambos os materiais, consiste na faixa de temperatura: entre $1000{ }^{\circ} \mathrm{C} \mathrm{e} 1200^{\circ} \mathrm{C}$ para as argilas expandidas e em torno do $900{ }^{\circ} \mathrm{C}$ para calcinação. Logo, o processo produtivo dos agregados calcinados apresenta a vantagem de ser menos oneroso que o dos expandidos.

A alternativa comumente empregada no Estado do Amazonas como agregado graúdo na pavimentação, especialmente para a composição de misturas asfálticas do tipo concreto betuminoso usinado a quente (CBUQ), é o seixo rolado, obtido por dragagem do leito de rios, procedimento que suscita acerbas críticas de ambientalistas, tendo-se em vista o profundo impacto causado aos ecossistemas fluviais. Interessa observar que o seixo, sendo agregado de forma esférica e textura superficial lisa, provoca redução no atrito entre suas partículas e, por conseguinte, diminui a resistência ao cisalhamento da mistura [5].

Diante desse campo de pesquisa, o presente trabalho busca a análise da viabilidade do emprego de agregado de argila calcinada na composição de misturas asfálticas do tipo CBUQ, em substituição ao seixo rolado. Para tanto, são empregados dois solos argilosos (obtidos de jazidas próximas ao corpo estradal da BR-319) para a confecção de agregados calcinados. Foram dosadas 3 misturas asfálticas enquadradas na Faixa $C$, do Departamento Nacional de Infra-estrutura de Transportes (DNIT), sendo 2 confeccionadas com agregado sintético e a terceira com seixo. O comportamento mecânico das referidas misturas é comparado por meio do módulo 
resiliente, determinado por compressão diametral.

Embora a extração de argila possa acarretar impactos ambientais, como os ocorridos com a extração do seixo rolado, muito criticada pelos ambientalistas, aqueles podem ser mínimos em relação a estes, desde que as atividades de exploração e fechamento da jazida sejam feitas de forma correta, de acordo com as particularidades da região, a definição das áreas de jazidas respeitem a margem de proteção de $50 \mathrm{~m}$ de floresta para os cursos d'água, além da observância de outras medidas conforme estabelece a legislação ambiental.

\section{MATERIAIS E MÉTODOS}

As amostras de solos finos adotadas como matéria-prima foram escolhidas, de início, por meio de critérios apontados pela prática, quais sejam, solos tipicamente adequados para produção de cerâmica. Conforme trabalhos desenvolvidos pelo Grupo de Geotecnia [6] e Batista [4], amostras que demonstram boa resistência mecânica à compressão manual, quando moldadas em forma de pelotas e secas naturalmente, apresentam características mecânicas apreciáveis para a produção de agregados. A Tabela I mostra a localização das 2 (duas) jazidas selecionadas para o presente trabalho.

Tabela I - Localização das amostras de solos finos selecionadas.

[Table I - Localization of selected fine graded soil samples.]

\begin{tabular}{cccc}
\hline \multicolumn{4}{c}{ Coordenadas } \\
Amostras & Localização & Latitude & Longitude \\
\hline A & S 03.54199 & W 060.41567 & AM-354-km 15-BD \\
B & S 04.24335 & W 060.83091 & BR-319-km 183 - BD \\
\hline
\end{tabular}

Foram realizados os procedimentos geotécnicos típicos à classificação dos solos, concernentes aos critérios da Highway Research Board of the American Association of State Highway and Transportation Officials (Transportation Research Board) - HRB-AASHTO (TRB) e do Sistema Unificado de Classificação de Solos - SUCS. Para tanto, determinou-se a textura, com observância aos procedimentos descritos na Norma Brasileira Registrada - NBR 7181 da Associação Brasileira de Normas Técnicas - ABNT [7] de modo a se obter as frações granulométricas que compõem cada amostra, bem assim os limites de liquidez e plasticidade, ABNT-NBR 6459 [8] e ABNT-NBR 7180 [9], respectivamente.

Após caracterização, procedeu-se à confecção dos agregados sintéticos de argila calcinada (ASAC). Cada solo foi submetido a procedimento manual de homogeneização com adição de água até atingirem uma umidade superior ao limite de plasticidade, permitindo a mudança de formas sem o aparecimento de trincas. Essa fase se mostrou de suma importância, uma vez que solos mal homogeneizados podem gerar agregados quebradiços, mais propensos à formação de trincas durante a queima ou de pouca resistência após a calcinação [6].

Posteriormente são moldadas massas de solo em formato cilíndrico medindo aproximadamente $15 \mathrm{~cm}$ de diâmetro e 30 $\mathrm{cm}$ de altura e, em seguida, passadas em telas com malha de nylon permitindo a obtenção de quatro graduações diferentes de agregados (entre 19,0 $\mathrm{mm}$ e 12,5 mm, 12,5 $\mathrm{mm}$ e 9,5 mm, $9,5 \mathrm{~mm}$ e $6,3 \mathrm{~mm}, 6,3 \mathrm{~mm}$ e $4,8 \mathrm{~mm}$ ). A malha das telas tem abertura referente à graduação desejada para os agregados produzidos. À medida que esses dispositivos atravessam o cilindro de solo, em seu eixo longitudinal são realizados cortes transversais nas seções superiores. Esse processo leva à produção de agregados em forma de paralelepípedo.

$\mathrm{Na}$ fase seguinte, os mesmos são submetidos ao processo de secagem natural à sombra. Esta fase também se mostrou importante no produto final. Em testes realizados pelo Grupo de Geotecnia da UFAM [6] e de acordo com Batista [4] foi constatado que o tempo de secagem prévia, se inferior ao necessário, influencia na qualidade podendo proporcionar agregados frágeis, facilmente quebráveis com as mãos. O tempo máximo para a secagem ocorreu em até quatro dias, sendo a mesma considerada satisfatória com base na mudança de coloração e quando os agregados não apresentavam brilho superficial.

A etapa subseqüente consiste em levar o material ao forno elétrico, dentro de jarros cerâmicos, devidamente preparados para esse fim. A queima é composta por uma fase inicial de aquecimento do forno, realizado de forma gradual e lenta, durante $5 \mathrm{a} 6 \mathrm{~h}$, até atingir cerca de $350{ }^{\circ} \mathrm{C}$. Posteriormente, realiza-se a queima propriamente dita, durante 5 a $6 \mathrm{~h}$, até o forno atingir $950{ }^{\circ} \mathrm{C}$. Ao final desta, o forno é desligado e deixado esfriar durante outras $6 \mathrm{~h}$ aproximadamente. Por fim, inicia-se abertura gradual do forno, de forma cuidadosa, visando a evitar choque térmico entre a temperatura ambiente e a do interior do dispositivo. A abertura completa só pode ser realizada quando os agregados estiverem a uma temperatura que permita manuseio humano.

Uma vez produzidos os agregados, são submetidos aos ensaios de qualificação das amostras, conforme estabelece a especificação do DNIT: Seleção expedita pelo Processo de Fervura - Ensaio de Autoclave [10], perda de massa após fervura [11] e desgaste por abrasão "Los Angeles" [12].

Para compor as misturas asfálticas, a serem avaliadas neste trabalho, foram empregados, além do agregado sintético, o seixo rolado e a areia de origem residual. Estes dois últimos compreendem materiais tipicamente utilizados em revestimentos do tipo CBUQ no Município de Manaus. Foram realizados ensaios de granulometria para os citados materiais, de acordo com a ABNT - NBR 7217 [13].

As amostras de ASAC's também foram caracterizadas segundo suas massas específicas dos grãos, massas específicas aparentes dos grãos e absorção de água, determinadas com base na ABNT - NBR 6458 [14]. A areia foi avaliada somente quanto sua massa específica dos grãos, segundo a ABNT - NBR 6508 [15]. O seixo foi analisado conforme a absorção de água e massa específica dos grãos por meio da 
norma ABNT - NBR 6458 [14]. Para cumprir a função de material de enchimento, empregou-se o tradicional cimento Portland.

O ligante asfáltico empregado nas misturas asfálticas foi o Cimento Asfáltico de Petróleo - CAP 50/70, também classificado quanto ao Performance Grade, como PG 58-22, conforme critérios Superpave [16]. Tal material foi fornecido pela Refinaria Isaac Sabbá (UN-Reman) ao presente estudo. O presente ligante é utilizado nas obras de pavimentação no Estado do Amazonas.

Empregou-se uma mistura para cada agregado graúdo, totalizando 3 misturas. Estas foram confeccionadas segundo Faixa C do DNIT [17], sugerida para composição de revestimento asfáltico destinado à faixa de rolamento. A partir das composições granulométricas, realizou-se dosagem das misturas conforme metodologia Marshall [18]. Para tanto, foram moldados 3 corpos de prova cilíndricos (101,5 mm de diâmetro e $63,5 \pm 0,5 \mathrm{~mm}$ de altura) referentes a cada um dos diversos teores de ligante. Foram empregadas faixas entre 4 e $6 \%$ de asfalto, para a Mistura $S$, e entre 6 e $8 \%$, para as Misturas $A$ e $B$.

Foram calculados os índices físicos de cada corpo de prova, sendo obtida uma média para cada teor de ligante empregado. O teor ótimo de ligante, também, foi avaliado de modo a se conseguir índice de vazios entre $3 \%$ e $5 \%$ e relação Betume-Vazios (RBV) entre $75 \%$ e $82 \%$.

Estudou-se o comportamento mecânico das misturas, segundo o módulo resiliente (MR). Este parâmetro constitui o módulo de elasticidade dos materiais, como no caso das misturas asfálticas. Sua finalidade radica em trazer a lume, de maneira ilustrativa, a rigidez da mistura no pavimento. Igualmente, pode ser utilizado como entrada de dados em análises numéricas, que, posteriormente, podem ser utilizadas para se aferir a falha do material, no tocante à deformação permanente, à fadiga e à resistência a carregamentos monotônicos. Foi obtido por meio de tração por compressão diametral, a partir do carregamento dinâmico em corpos de prova cilíndricos.

Procedeu-se, também, à determinação da resistência à ruptura à tração (RT) de cada mistura, antes de cada ensaio MR. Para a consecução de tal finalidade, lançou-se mão da metodologia especificada pelo DNIT, que faz uso da compressão estática diametral. As cargas são aplicadas segundo uma taxa de $0,8 \mathrm{~mm} / \mathrm{s}$, em friso e com corda de 12,7 $\mathrm{mm}$. Para cada mistura os resultados foram obtidos a partir da média aritmética de, pelo menos, três corpos de prova.

Os resultados dos ensaios de resistência à tração são importantes para a determinação do módulo resiliente, porquanto da carga de ruptura do primeiro ensaio é calculada a carga a ser empregada no segundo experimento. Fez-se uso de carga cíclica de geometria haversine, com pico de tensão calculado em $30 \%$ da resistência à tração (RT). Os intervalos de aplicação dessa carga foram de $0,1 \mathrm{~s}$ de carregamento e $0,9 \mathrm{~s}$ de repouso, concernente a uma freqüência de $1 \mathrm{~Hz}$.

O dispositivo de aplicação da carga, utilizado no ensaio MR, é similar ao do experimento de resistência à tração. As deformações diametrais foram medidas por meio de dispositivo tipo Linear Variable Differential Transformers - LVDT e o módulo de Poisson foi estimado em 0,35 [19]. Aplicaram-se, inicialmente, 400 ciclos de carga para condicionamento, em seguida cinco pulsos para determinação dos módulos. Considerou-se como valor do $\mathrm{MR}$, relativo àquele ensaio, a média aritmética dos valores alcançados para os cinco últimos pulsos, e concernentes à média aritmética de, no mínimo, três corpos de prova, para cada mistura.

\section{RESULTADOS E DISCUSSÃO}

As frações granulométricas que compõem cada amostra de solo estão apresentadas na Tabela II. A Tabela III lista os limites de consistência das amostras selecionadas (Tabela III). Dos resultados apresentados abaixo se classifica a Amostra $A$ como sendo um solo classe A7-5, e a Amostra $B$ como A7-6, segundo o supracitado critério HRB-AASHTO. Em relação ao segundo critério SUCS, ambas as amostras são enquadradas como argilas inorgânicas com alta plasticidade $(\mathrm{CH})$.

Tabela II - Composição textural das amostras selecionadas. [Table II - Textural composition of selected samples.]

\begin{tabular}{cccc}
\hline Amostra & Areia & Silte & Argila \\
\hline A & $4 \%$ & $22 \%$ & $73 \%$ \\
B & $16 \%$ & $45 \%$ & $39 \%$ \\
\hline
\end{tabular}

Tabela III - Limites de consistência das amostras selecionadas.

[Table III - Consistency limits of selected samples.]

\begin{tabular}{cccc}
\hline Amostra & $\begin{array}{c}\text { Limite de } \\
\text { Liquidez }\end{array}$ & $\begin{array}{c}\text { Limite de } \\
\text { Plasticidade }\end{array}$ & $\begin{array}{c}\text { Índice de } \\
\text { Plasticidade }\end{array}$ \\
\hline A & $84 \%$ & $36 \%$ & $48 \%$ \\
B & $57 \%$ & $23 \%$ & $34 \%$ \\
\hline
\end{tabular}

A Tabela IV mostra os resultados dos ensaios de qualificação aos quais foram submetidos os ASAC"s. Oresultado discriminado nesta tabela, mostra que a Amostra $B$ não poderia ser empregada como agregado graúdo, tendo-se em vista seu alto grau de desgaste por abrasão. Contudo, trabalhos anteriores realizados pelo Grupo de Geotecnia da UFAM [20] têm demonstrado que, mesmo diante desse resultado negativo, misturas com esses agregados de argila apresentam resistência mecânica apreciável. Assim, costuma-se avaliar a viabilidade desse material não apenas diante desse resultado, mas segundo o desempenho mecânico da mistura.

A Fig. 2 apresenta as curvas granulométricas obtidas para os ASAC's e o seixo rolado. O gráfico demonstra certa discrepância entre os agregados sintéticos (ASAC) e o seixo rolado. Este fato foi proposital, tratando-se de uma opção no momento da produção dos agregados de argila, objetivandose a obtenção de um material mais graúdo. 
Tabela IV - Ensaios de qualificação dos agregados. [Table IV - Aggregates qualification tests.]

\begin{tabular}{lcccc}
\hline \multirow{2}{*}{ Ensaio } & \multirow{2}{*}{ Norma } & Valores & \multicolumn{2}{c}{ Amostra } \\
& & Limites & A & B \\
\hline $\begin{array}{l}\text { Variação } \\
\text { de textura }\end{array}$ & DNER & Não & Não & Não \\
$\begin{array}{l}\text { e forma } 23 / 94 \\
\text { Perda de }\end{array}$ & Varia & Varia & Varia \\
$\begin{array}{l}\text { de massa } \\
\text { após fervura }\end{array}$ & DE 225/94 & Máx & $0,04 \%$ & $0,07 \%$ \\
$\begin{array}{l}\text { Desgaste por } \\
\text { abrasão }\end{array}$ & DNER & Máx & $24 \%$ & $63 \%$ \\
"Los Angeles" & ME 222/94 & $45 \%$ & & \\
& {$[12]$} & & & \\
\hline
\end{tabular}

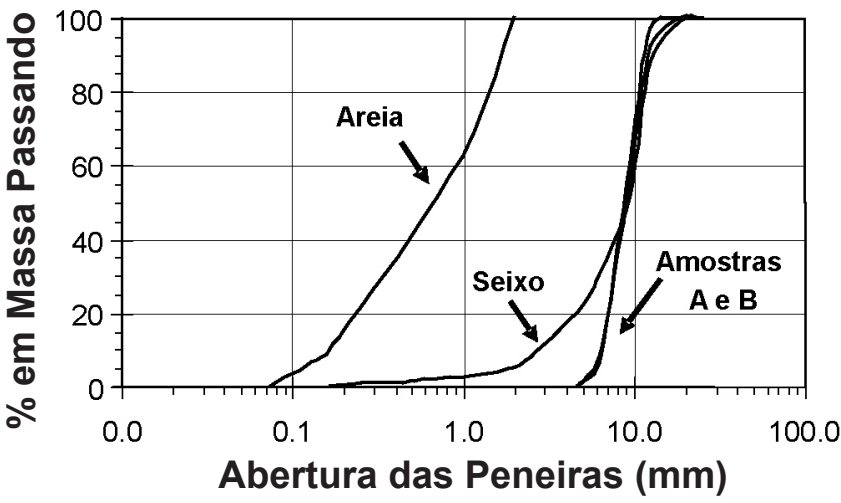

Figura 2: Composição granulométrica dos agregados. [Figure 2: Aggregates grain size.]

As amostras de ASAC apresentaram massas específicas dos grãos, próximas aos valores do seixo rolado, ou seja, as amostras $A$ e $B$ do agregado sintético alcançaram 2,649 g/ $\mathrm{cm}^{3}$ e $2,672 \mathrm{~g} / \mathrm{cm}^{3}$, respectivamente, e o seixo, $2,622 \mathrm{~g} / \mathrm{cm}^{3}$. A massa específica aparente dos grãos das amostras $A$ e $B$, mostraram resultados iguais a $1,649 \mathrm{~g} / \mathrm{cm}^{3}$ e $1,661 \mathrm{~g} / \mathrm{cm}^{3}$, respectivamente. Quanto à massa específica dos grãos da areia obteve-se um valor igual a $2,625 \mathrm{~g} / \mathrm{cm}^{3}$.

As amostras de argila calcinada indicaram alto potencial de absorção: $22 \%$ para a Amostra $A$ e $23 \%$ para a Amostra $B$, enquanto o seixo não apresentou esta característica. Este resultado demonstra que as misturas compostas por argila calcinada (ASAC) provavelmente necessitarão de uma maior quantidade de ligante, tendo-se em vista que uma parcela deste material poderá ser absorvida. Quanto à abrasão Los Angeles, o seixo rolado apresentou $35 \%$ de desgaste, sendo mais frágil que a Amostra $B$ e mais resistente que a Amostra $A$.

A caracterização do lote de cimento Portland utilizado denotou que o material apresenta massa específica real de $3,150 \mathrm{~g} / \mathrm{cm}^{3}$ [21] e granulometria condizente ao que é padronizado para filer, pela norma do DNIT [22].

As curvas granulométricas das misturas estudadas são apresentadas na Fig. 3. Analisando-se o comportamento das mesmas, pode-se observar que as misturas com argila calcinada (Misturas $A$ e $B$, referentes às Amostras $A$ e $B$, respectivamente) apresentam uma maior fração graúda, assim como uma pequena descontinuidade no que se refere à fração localizada entre os diâmetros de 4,75 mm e 1,18 $\mathrm{mm}$. A mistura com seixo (S), por sua vez, apresenta uma distribuição mais uniforme das frações.

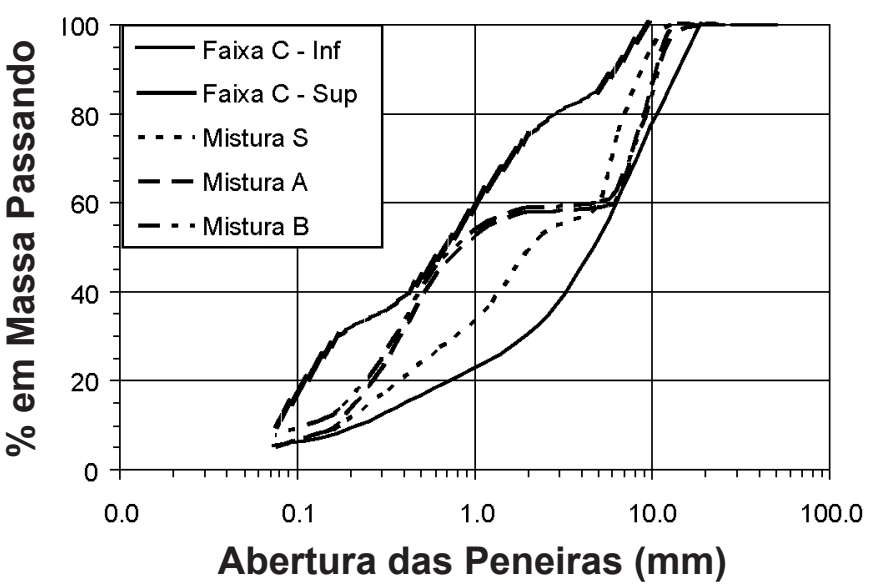

Figura 3: Curva granulométrica das misturas avaliadas.

[Figure 3: Grain size of tested mixtures.]

Os teores ótimos de ligante e os índices físicos das mistura são indicados na Tabela V. Conforme esperado, a mistura $S$ apresentou menor teor ótimo de ligante, para valores de índices físicos equivalentes aos das misturas $A$ e $B$. A absorção de ligante, por parte do agregado sintético (ASAC), apresenta-se como fator a ser considerado quando das dosagens de outras misturas com o mesmo material. Sendo os índices físicos muito próximos, das misturas A e $\mathrm{B}$, podem-se restringir as análises posteriores unicamente quanto à forma e à textura dos agregados, além da composição das misturas quanto à sua granulometria.

Tabela V - Teores ótimos de ligante e Índices físicos das misturas.

[Table V - Optimum asphalt content and physical index of mixtures.]

\begin{tabular}{cccc}
\hline Mistura & $\begin{array}{c}\text { Teor de } \\
\text { Ligante (\%) }\end{array}$ & $\begin{array}{c}\text { Índice de } \\
\text { Vazios (\%) }\end{array}$ & $\begin{array}{c}\text { RBV } \\
(\%)\end{array}$ \\
\hline S & 5,5 & 4,2 & 75,0 \\
A & 7,6 & 4,0 & 77,1 \\
B & 7,7 & 4,0 & 78,3 \\
\hline
\end{tabular}

$\mathrm{Na}$ Tabela VI mostram-se os valores obtidos para a resistência à tração (RT) das misturas. Dos valores apresentados, observa-se que a mistura $S$ possui a menor resistência à tração. A mistura $B$, com agregado de argila calcinada de alto desgaste por abrasão Los Angeles, obteve a maior resistência, corroborando a assertiva de que este parâmetro não é suficientemente confiável para se reprovar 
ou se aprovar um agregado sintético (ASAC). O seixo rolado, por apresentar forma e superfície que prejudicam o atrito entre as partículas, não imprime tal resistência às misturas. Os valores mais altos da RT referem-se às misturas com ASAC, conferindo crédito ao uso desse material.

Tabela VI - Resistência à Tração das misturas. [Table VI - Tensile Strength of mixtures.]

\begin{tabular}{lccc}
\hline & Mistura S & Mistura A & Mistura B \\
\hline $\begin{array}{l}\text { Força Máxima (kN) } \\
\text { Resistência à }\end{array}$ & 6,210 & 8,540 & 9,640 \\
Tração (MPa) & 0,600 & 0,830 & 0,940 \\
Desvio Padrão (sd) & 0,025 & 0,005 & 0,020 \\
\hline
\end{tabular}

Na Tabela VII apresentam-se os valores dos módulos resilientes (MR) alcançados para as misturas. Confrontandose estas misturas, percebem-se resultados superiores das compostas com argila calcinada (ASAC), em relação àquelas confeccionadas com seixo. A mistura $B$ apresenta módulo superior em $54 \%$ ao da mistura $S$. Esse fato por si só contribuiria para revestimentos de maior resistência. A mistura $A$ mostrou um valor mais baixo, porém em $27 \%$ superior ao da mistura com seixo, o que já representa um ganho significativo.

Tabela VII - Módulo Resiliente das misturas. [Table VII-Resilient Modulus of mixtures.]

\begin{tabular}{lccc}
\hline & Mistura S & Mistura A & Mistura B \\
\hline $\begin{array}{l}\text { Módulo } \\
\text { Resiliente (MPa) }\end{array}$ & 991 & 1256 & 1528 \\
Desvio Padrão (sd) & 25,405 & 58,897 & 44,804 \\
& & & \\
\hline
\end{tabular}

Na Fig. 4 têm-se as deformações horizontais, registradas pelos dispositivos LVDT, para os cinco últimos pulsos de carga. Observa-se que a mistura $A$ apresentou as maiores deformações, seguida da misturas $S$ e $B$, respectivamente. Da análise desse gráfico, conclui-se, além disso, que a mistura $B$ mostrou a menor susceptibilidade às solicitações dinâmicas impostas pelo tráfego. Todavia, a simples constatação das variações entre os gráficos não representa, com fidelidade, o que se deseja para misturas asfálticas com agregado sintético. Se assim fosse, poder-se-ia dizer que a mistura $A$ teria uma grande tendência às deformações, quando comparada à mistura $S$. Recomendável proceder a uma outra análise, por meio da Fig. 5, que mostra a regressão a partir dos picos de deformação (registrado no dispositivo LVDT) iniciais de cada pulso.

Pela Fig. 5 nota-se que a mistura $B$ apresentou as retas de pico e de base com os menores coeficientes angulares, evidência de que essa mistura apresenta, de fato, a menor deformação dentre as três misturas avaliadas. O uso de uma

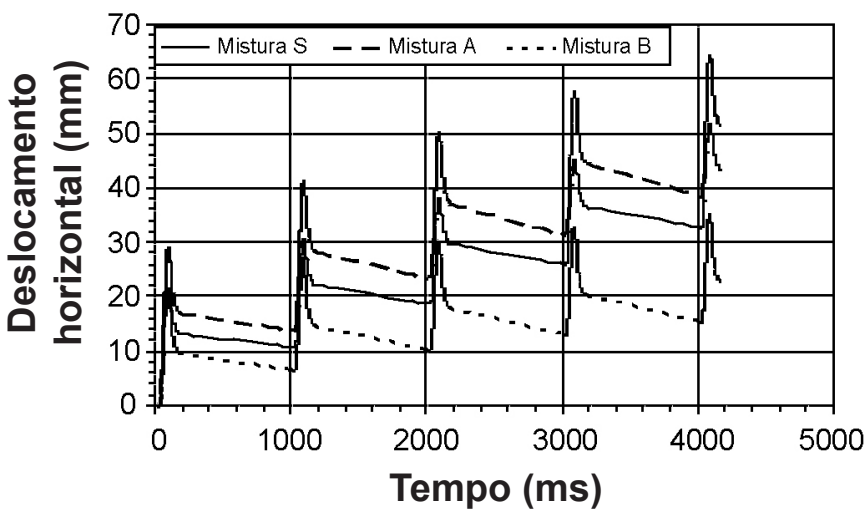

Figura 4: Deformação medida para os cinco últimos pulsos de carga.

[Figure 4: Deformation measured for the five last load pulses.]

mistura dessa natureza, em uma situação real, importaria em pequena tendência quanto à formação de deformações permanentes, ao confrontá-las com misturas confeccionadas com seixo rolado.

A mistura $A$ mostrou coeficientes angulares maiores que os referentes à mistura $S$, representando um ponto negativo desta em relação à mistura confeccionada com agregado natural. Saliente-se um fator importante nesta análise, que vem a ser a distância relativa entre as retas de pico e de base entre cada mistura. Este distanciamento representa o quanto uma mistura consegue recuperar a deformação antes que o próximo ciclo se inicie. Sintetiza, em outras palavras, a recuperação elástica esperada para aquela mistura. Ao mesmo tempo, a observação do aludido gráfico demonstra que as misturas $A$ e $B$ apresentam recuperações muito próximas. Destarte, confirma-se que, apesar de deter menores deformações que a mistura $A$, a mistura $S$ apresenta tendência muito pequena de recuperar as deformações sofridas, manifestando maior susceptibilidade às deformações plásticas. Na prática, isso corresponderia a dizer que uma mistura confeccionada com agregado natural (seixo) apresenta uma tendência menor de

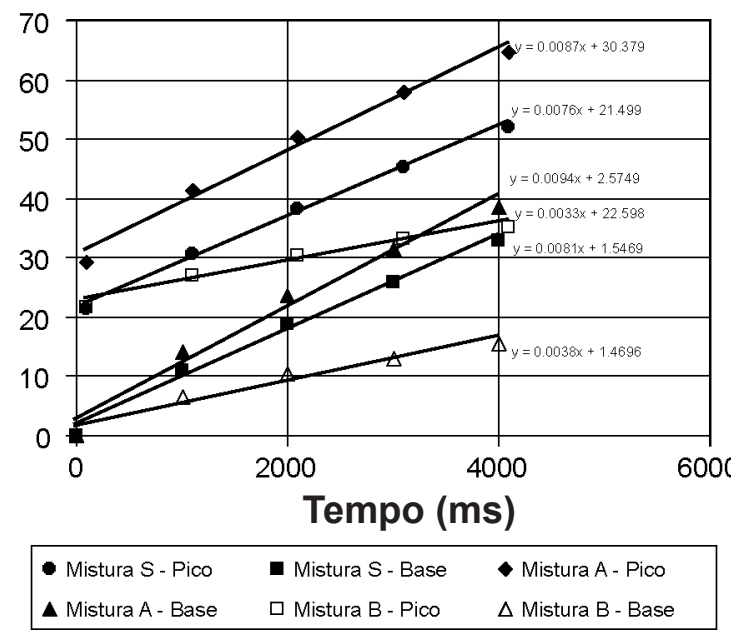

Figura 5: Regressão para os picos de deformações. [Figure 5: Regression for the deformation peaks.] 
recuperar-se de uma deformação, quando comparada a uma outra, confeccionada com agregado sintético (ASAC).

Nesse contexto, avalia-se que a textura superficial e a forma do seixo rolado contribuem para sua menor tendência para recuperar-se das deformações sofridas. $\mathrm{O}$ menor atrito entre as partículas pode tornar menos eficaz a mistura, quando solicitada pelos carregamentos. No caso do carregamento cíclico (passagem de veículos), a tendência em se apresentarem deformações plásticas importa maior susceptibilidade à formação de trilhas de roda no revestimento.

Ante o quadro acima delineado, deduz-se que o emprego de agregados sintéticos de argila calcinada (ASAC) se apresenta como adequada alternativa ao uso do seixo rolado, cuja extração implica em impacto ambiental. O uso dessa opção também deve contemplar a questão ambiental, uma vez que, desse modo, políticas públicas de exploração de jazidas de argila podem ser adotadas de forma lícita. O interesse público se releva presente em função do ganho técnico obtido quanto ao comportamento mecânico das misturas com ASAC. Ressalte-se que os agregados sintéticos apresentam imensa flexibilidade no que concerne às formas que podem ser produzidos, o que é uma vantagem, posto que se pode adaptar esse fator à necessidade e às limitações dos meios produtivos.

\section{CONCLUSÕES}

O emprego do seixo rolado como agregado nas misturas asfálticas implica não apenas impacto ambiental desfavorável, bem como, em retrospecto histórico, opção de menor valor técnico. $\mathrm{O}$ uso de agregados sintéticos de argila calcinada (ASAC) se revela alternativa regional viável, dada a abundância, no Estado do Amazonas, da matériaprima (argila) necessária para a produção dessa espécie de material.

Misturas asfálticas confeccionadas com agregados sintéticos de argila calcinada (ASAC) apresentam tendência maior ao consumo de ligante, tendo-se em vista seu alto potencial de absorção e, proporcionam maiores resistências à tração e módulos resiliente, quando comparadas com as misturas asfálticas elaboradas com agregado natural. As misturas asfálticas confeccionadas com agregados provenientes da amostra $B$ da BR-319 se destacaram das demais por apresentarem baixa tendência à deformação, assim como por ostentarem considerável recuperação elástica. As misturas asfálticas oriundas de agregados da amostra $A$, contudo, demonstraram maior susceptibilidade às deformações, embora sua recuperação elástica seja compatível com a da amostra anterior. Os resultados demonstraram, igualmente, uma menor susceptibilidade das misturas asfálticas formadas por agregados da Amostra $B$ às deformações permanentes e a conseqüente formação de trilha de roda. A maior rigidez dessas misturas asfálticas evidencia a viabilidade do uso dos agregados sintéticos (ASAC) na composição de revestimentos destinados aos pavimentos asfálticos. Também é importante ressaltar a liberdade de se produzir tal material, segundo uma forma que venha atribuir maior resistência à mistura.

Verificou-se que amostras obtidas a partir de jazidas encontradas ao longo do corpo estradal da BR-319 se mostraram aptas à produção de agregados sintéticos de qualidade técnica, representando importante fator a ser analisado quando da escolha dos materiais para obras de recuperação dessa relevante rodovia federal para a economia do Estado do Amazonas.

\section{REFERÊNCIAS}

[1] DNER, Condições de Rodovias, Disponível: www1.dnit. gov.br/rodovias/condicoes/am.htm, obtido em 08/09/2006.

[2] L. A. Fernandes F., Geologia, mineralogia, geoquímica dos lateritos de Manaus-Amazonas, Diss. Mestrado, UFPA, Belém, PA (1996).

[3] F. H. Norton, Introdução à Tecnologia Cerâmica, $1^{a}$ Ed., Edgar Blucher, Rio de Janeiro (1973) 324.

[4] F. G. S. Batista, Caracterização Física e Mecanística dos Agregados de Argila Calcinada Produzidos com Solos Finos da BR-163/PA, Diss. Mestrado, IME, Rio de Janeiro, RJ (2004).

[5] C. A. da Frota, D. M. de Melo, F. R. G. Nunes, Anais da V Jornadas Luso-Brasileiras de Pavimentos: Políticas e Tecnologias, ANDIT, Recife, PE (2006) cdrom, trabalho V48.

[6] C. A. da Frota, C. L. da Silva, M. G. R. dos Santos, R. V. Pereira, Anais da $35^{\mathrm{a}}$ Reunião Anual de Pavimentação, ABPv, Rio de Janeiro, RJ (2004) cdrom, trabalho 022.

[7] ABNT, NBR 7181, Solo - Análise granulométrica, ABNT, Rio de Janeiro (1984).

[8] ABNT, NBR 6459, Solo - Determinação do limite de liquidez, ABNT, Rio de Janeiro (1984).

[9] ABNT, NBR 7180, Solo - Determinação do limite de plasticidade, ABNT, Rio de Janeiro (1984).

[10] DNER, ME 223/94, Argilas para a fabricação de agregados sintéticos de argila calcinada - Seleção expedita pelo Processo de Fervura, DNIT, Rio de Janeiro (1994).

[11] DNER, ME 225/94, Agregado sintético de argila calcinada - Determinação da Perda de Massa após Fervura, DNIT, Rio de Janeiro (1994).

[12] DNER, ME 222/94, Agregado sintético fabricado com argila - Desgaste por Abrasão, DNIT, Rio de Janeiro (1994).

[13] ABNT, NBR 7217, Agregados - Determinação da composição granulométrica, ABNT, Rio de Janeiro (1987).

[14] ABNT, NBR 6458, Grãos de pedregulho retidos na peneira de \# 4,8 mm - Determinação da massa específica, da massa específica aparente e da absorção de água, ABNT, Rio de Janeiro (1984).

[15] ABNT, NBR 9937, Grãos de solo que passam na peneira de \# 4,8 mm - Determinação da massa específica, ABNT, Rio de Janeiro (1984).

[16] SHRP (1995). Superior Performing Asphalt Pavements (Superpave): The Product of SHRP Asphalt Research Program. Superpave Series N. 1. 
[17] DNER, ES 313/97, Pavimentação - Concreto Betuminoso, DNIT, Rio de Janeiro (1997).

[18] DNER, ME 043/95, Misturas betuminosas a quente - Ensaio Marshall, DNIT, Rio de Janeiro (1995).

[19] Huang Y. H., Pavement Analysis and Design, Second Edition, Pearson Education, Inc, Upper Saddle River, NJ (2004) 329.

[20] F. R. G. Nunes, Caracterização Mecânica de Misturas
Asfálticas Confeccionadas com Agregados Sintéticos de Argila Calcinada Quanto a Deformação Permanente, Diss. Mestrado, UFCE, Fortaleza, CE (2006).

[21] DNER, ME 085/94, Material finamente pulverizado - Determinação da massa específica real, DNIT, Rio de Janeiro (1994).

[22] DNER, ME 367/97, Material de enchimento para misturas betuminosas, DNIT, Rio de Janeiro (1997).

(Rec.15/11/2006, Rev. 23/01/2007, Ac. 12/02/2007) 